\title{
Low-protein diet supplemented with ketoacids delays the progression of diabetic nephropathy by inhibiting oxidative stress in the KKAy mice model
}

\author{
Dongmei Liu†, Ming Wu†, Lin Li†, Xiang Gao, Bo Yang, Shuqin Mei, Lili Fu and Changlin Mei* \\ Department of Nephrology, Shanghai Changzheng Hospital, Kidney Institute, Second Military Medical University, Shanghai, \\ 200003, People's Republic of China \\ (Submitted 24 February 2017 - Final revision received 11 October 2017 - Accepted 20 October 2017-First published online 6 December 2017)
}

\section{Abstract}

Diabetic nephropathy (DN) is a major cause of chronic kidney disease. We aimed to investigate the effect of the low-protein diets (LPD) supplemented with ketoacids (LPD + KA) in KKAy mice, an early type 2 DN model. KKAy mice were treated with normal protein diet (NPD), LPD or LPD + KA from 12 to 24 weeks of age. A period of 12-week treatment with LPD significantly reduced albuminuria as compared with that observed after NPD treatment. Treatment with LPD + KA further reduced albuminuria as compared with that observed with LPD treatment alone. Moreover, LPD treatment reduced mesangial expansion, thickness of glomerular basement membrane and the severity of the podocyte foot process effacement in KKAy mice; these effects were more pronounced in KKAy mice treated with LPD + KA. Both LPD and LPD + KA treatments slightly reduced total body weight, but had no significant effect on kidney weight and blood glucose concentrations when compared with NPD-treated KKAy mice. LPD treatment slightly attenuated oxidative stress in kidneys as compared with that observed in NPDtreated KKAy mice; however, LPD + KA treatment remarkably ameliorated oxidative stress in diabetic kidneys as shown by decreased malondialdehyde concentrations, protein carbonylation, nitrotyrosine expression and increased superoxide dismutase expression. Nutritional therapy using LPD + KA confers additional renal benefits as compared with those of LPD treatment alone in early type 2 DN through inhibition of oxidative stress.

Key words: Ketoacids: Low-protein diets: Diabetic nephropathy: Oxidative stress

Diabetes mellitus (DM) is a metabolic disorder that is characterised by impaired insulin secretion and poor response to insulin $^{(1,2)}$. Type 2 diabetes mellitus (T2DM) accounts for approximately $90 \%$ of all patients with $\mathrm{DM}^{(2)}$. Diabetic nephropathy (DN) affects approximately one-third of all patients with $\mathrm{DM}$, and it is a major cause of chronic kidney disease (CKD) and end-stage renal disease (ESRD) ${ }^{(3)}$.

Standard approach for management of DN includes control of blood pressure through the blockade of renin-angiotensin system (RAS) and glycaemic control; however, these interventions may not prevent the progression of DN to $\mathrm{ESRD}^{(3,4)}$. Thus, development of additional therapies to prevent progression of DN is a key research imperative.

Low-protein diet (LPD) has been designed to reduce protein overload and to ameliorate glomerular haemodynamics in patients with kidney disease ${ }^{(5)}$. Indeed, the beneficial effects of LPD have been shown in various rodent models of kidney disease including $\mathrm{DN}^{(6,7)}$. However, definitive evidence of the clinical benefit of protein restriction in patients with kidney disease is yet to be obtained ${ }^{(8-10)}$. Recently, Shah \& Patel et al. ${ }^{(11)}$ demonstrated that LPD could be prescribed to patients with slowly progressive CKD in the early stages (stages 1-3), but not to CKD patients in the late stages (stages 4 and 5). However, patients with DN were not included in this study. The effect of LPD therapy on nutritional status of patients with renal disease is a valid concern ${ }^{(10)}$; this is particularly relevant in the case of patients with DN in whom impaired response to insulin leads to loss of body mass ${ }^{(6)}$. To reduce the risk of malnutrition due to LPD, use of a treatment strategy based on restricted protein intake in combination with administration of keto analogues of amino acids, to delay the progress of CKD, was assessed in several studies ${ }^{(12)}$. Ketoacids (KA) have excess $N$ residues, which can be used for production of essential amino acids (EAA). Use of LPD supplemented with KA (LPD + KA) was shown to maintain muscle mass and decrease loss of body weight in a rat model of type $2 \mathrm{DN}^{(13)}$. In a type $1 \mathrm{DN}$ rat model, LPD + KA was shown to improve nutritional status and reduce urinary protein excretion as compared with that with LPD treatment alone ${ }^{(14)}$. The beneficial effects of LPD $+\mathrm{KA}$ in type $2 \mathrm{DN}$, particularly at an early stage, are not yet known.

Abbreviations: CKD, chronic kidney disease; DN, diabetic nephropathy; GBM, glomerular basement membrane; KA, ketoacids; LPD, low-protein diet; LPD + KA, LPD supplemented with KA; MDA, malondialdehyde; NPD, normal protein diet; NT, nitrotyrosin; SOD, superoxide dismutase.

* Corresponding author: Professor C. Mei, fax +862163521416, email chlmei1954@126.com

$\dagger$ These authors contributed equally to this paper. 
Histological changes including glomerular hypertrophy, mild mesangial expansion and thickening of the glomerular capillary walls can be detected as early as 2 years after the diagnosis of $\mathrm{DM}^{(15)}$. Microalbuminuria is a sign of early-stage $\mathrm{DN}$, which appears before changes in serum creatinine levels ${ }^{(2,16)}$. Early detection of $\mathrm{DN}$ and prevention of disease progression in the early stages is a key clinical imperative to forestall irreversible renal injury ${ }^{(1)}$

Oxidative stress is a trigger for $\mathrm{DN}$, which is caused by the hyperglycaemic status and the consequent renal accumulation of advanced glycation end products ${ }^{(17)}$. The imbalance in the redox state in DN is attributable to the increased production of oxidants or reactive oxygen species (ROS), which overwhelms the local antioxidant capacity ${ }^{(1,18)}$. The classical markers of oxidative stress include the products of lipid peroxidation (4-hydroxynonenal, malondialdehyde (MDA)) ${ }^{(19,20)}$ and protein carbonyl groups; these are abnormally expressed in $\mathrm{DN}^{(21)}$. Oxidative-stress-induced pathological changes in DN such as albuminuria, proteinuria, glomerulosclerosis and tubuleinterstitial fibrosis are mediated by multiple molecular signals $^{(22,23)}$. Animal studies have shown that inhibition of oxidative stress attenuates the progression of $\mathrm{DN}^{(24-26)}$

We previously found that the LPD + KA treatment displayed an additional antioxidant effect in 5/6 nephrectomised rats as compared with their counterparts treated with LPD alone ${ }^{(27,28)}$. It is not known whether LPD + KA treatment attenuates oxidative stress in DN. In the present study, we aimed to investigate the effect of LPD + KA in KKAy mice, which is a mouse model of early type $2 \mathrm{DN}^{(29)}$. We hypothesised that the LPD + KA exerts a renoprotective effect in early $\mathrm{DN}$ by reducing the degree of oxidative stress.

\section{Methods}

\section{Experimental animals and treatment protocol}

Male 8-week-old KKAy mice were obtained from the Institute of Laboratory Animal Science, Chinese Academy of Medical Sciences, and male 8-week-old C57BL/6 J mice were obtained from the Second Military Medical University. All animals were maintained according to local regulations and guidelines. All mice were fed adaptively with the normal protein diet (NPD, $22 \%$ casein protein) for 4 weeks. Subsequently, the KKAy mice were divided into three groups, which were administered different diets: NPD ( $n$ 10); LPD (LPD, $6 \%$ casein protein; $n 10$ ); and $\mathrm{LPD}+\mathrm{KA}(\mathrm{LPD}+\mathrm{KA}, 5 \%$ casein protein added $1 \% \mathrm{KA}$; $n$ 10). C57BL/6J mice were used as a control group and fed NPD. All diets contained the same amount of energy content $(14.7 \mathrm{~kJ} / \mathrm{g})$, vitamins and minerals, and were formulated according to the recommendations of the American Institute of Nutrition for rodent diets (AIN-93G) ${ }^{(30)}$. The diet formula is listed in Table 1. KA ( $\alpha$-ketoacids compound powder) were provided by Fresenius Kabi. The KA compound powder includes the following components ${ }^{(31)}$ : four KA analogues of the EAA (valine, leucine, isoleucine and phenylalanine); the hydroxyacid analogues of methionine; 4 EAA (lysine acetate, threonine, tryptophan, histidine) and L-tyrosine. The nutritional interventions lasted for 12 weeks and animals were killed at 24 weeks of age.
Table 1. Diet formula

\begin{tabular}{lccc}
\hline Ingredients & NPD (\%) & LPD (\%) & LPD + KA (\%) \\
\hline Casein (92\%) & 24 & 6.5 & 5.4 \\
KA & 0 & 0 & 1 \\
Maize starch & 47.5 & 65 & 65.1 \\
Glucose & 10 & 10 & 10 \\
Cellulose & 5.0 & 5.0 & 5.0 \\
Sesame oil & 7.0 & 7.0 & 7.0 \\
Mineral mix & 3.5 & 3.5 & 3.5 \\
Vitamin mix & 1.0 & 1.0 & 1.0 \\
Choline chloride & 0.25 & 0.25 & 0.25 \\
L-Cys & 0.3 & 0.3 & 0.3 \\
Total protein & 22 & 6 & 5 \\
\hline
\end{tabular}

NPD, normal protein diet; LPD, low-protein diets; LPD + KA, LPD supplemented with ketoacids.

The experimental protocol of the current study was approved by the Animal Care Committee at the Second Military Medical University, Shanghai, China.

\section{Blood, urine and tissue sample collection}

Blood and urine samples were collected at the age of 12, 16, 20 and 24 weeks. Before collection of blood samples, the mice were fasted for $6 \mathrm{~h}$. Under short anaesthesia with diethyl ether (MB0678; Meilunbio), 300-500 $\mu$ l of blood sample was obtained through the inner canthal orbital vein. Fasting blood glucose level was measured immediately using the blood glucose meter (ACCU-CHEK ${ }^{\circledR}$ Performa Nano; Roche). Blood samples were collected into serum separator tubes. After clot formation, the samples were centrifuged at $4000 \mathrm{rpm}$ for $10 \mathrm{~min}$ at $4{ }^{\circ} \mathrm{C}$ and serum was collected. Urine samples, $24 \mathrm{~h}$, were collected with the use of metabolic cages. Urine samples were centrifuged at $2000 \mathrm{rpm}$ for $10 \mathrm{~min}$ at $4^{\circ} \mathrm{C}$. The serum and urine samples were stored at $-80^{\circ} \mathrm{C}$ before further processing. Albumin concentration in serum and 24-h urine was measured using a commercial ELISA assay kit (ab108792; Abcam) with a detection range from 1.56 to $400 \mu \mathrm{g} / \mathrm{l}$ by the colorimetric detection method (Microplate Reader-ST-360; Kehua). According to the product information and instructions, the calculated overall intra-assay $\mathrm{CV}$ is $4.5 \%$, and inter-assay $\mathrm{CV}$ is $9.9 \%$. Creatinine concentrations in serum and 24-h urine were measured using a commercial kit ${ }^{(32)}$ (ab65340; Abcam) with a detection range from 4 to $20 \mu \mathrm{mol} / \mathrm{l}$ by the fluorometric detection method (SpectraMax i3x; Molecular Devices). According to the protocols ${ }^{(33)}$, each sample was assayed for a minimum of two replicates, and duplicates were within $20 \%$ of the mean value.

At 24 weeks of age, mice were anaesthetised by injection of sodium pentobarbital $(70 \mathrm{mg} / \mathrm{kg}$, intraperitoneal injection, 1507002; Sigma) and were killed to collect kidney samples ${ }^{(34)}$. Half of the kidneys were fixed in $4 \%$ paraformaldehyde and embedded in paraffin. Some of the renal cortical tissues were fixed in $2.0 \%$ glutaraldehyde (UFJ00964; Junruishengwu) and stored at $4^{\circ} \mathrm{C}$; these were used for the examination of glomerular basement membrane (GBM) and podocytes under a transmission electron microscope (H-600; Hitachi) ${ }^{(35)}$. The remaining renal cortical and medullary tissues were frozen in liquid $\mathrm{N}_{2}$ for further protein analysis. 


\section{Histological analysis and electron microscopy}

Paraffin-embedded renal samples were sliced into 3- $\mu \mathrm{m}$ sections with a pathological microtome (RM2135; Leica). The slides were stained using periodic acid-Schiff (PAS) kit (395B; Sigma) to evaluate glycogen deposition and mesangial expansion ${ }^{(36)}$. The mesangial expansion was assessed in a blinded manner using a semi-quantitative analysis, as described elsewhere ${ }^{(37)}$. In brief, twenty cortical glomeruli cut at vascular pole per kidney were used for morphometric analysis. The amount of mesangial extracellular matrix was identified by PAS-positive material in the mesangium; the glomerular area was also traced along the outline of capillary loop using Image-Pro Plus 6.0 (Media Cybernetics Inc.). The percentage of mesangial matrix occupying the selected glomerular tuft area was then calculated, and the relative mesangial area was expressed as a percentage of the glomerular surface area.

To measure the GBM thickness, three electron micrographs of non-overlapping fields were obtained for each glomerulus at a constant magnification of $10000 \times$. An average of ten points was measured per case, after which the arithmetic means with their standard errors for GBM thickness were determined for each animal $^{(15)}$. Finally, the arithmetic means with their standard errors for each treatment group were calculated and recorded.

\section{Protein analysis}

Total renal (including cortex and medulla) tissues were homogenised using a homogeniser (Pro200, Bio-Gen Series; PRO Scientific Inc.) in ice-cold RIPA lysis buffer $(1 \mu \mathrm{l} / \mathrm{mg}$ tissue, P0013B; Beyotime), which contains 1/50 (v/v) protease and phosphatase inhibitor cocktails (P1045; Beyotime). Tissue homogenate was centrifuged at $12000 \mathrm{rpm}$ for $15 \mathrm{~min}$ at $4^{\circ} \mathrm{C}$, and the supernatant was collected for further analysis. Total protein concentration was determined by the Bradford protein assay (P0006-2; Beyotime) ${ }^{(38)}$.

The oxyblot protein oxidation detection kit (S7150; Chemicon International Temecula) was used according to the manufacturer's instructions to assess the level of protein carbonyl groups $^{(39)}$. The level of oxidatively modified proteins was quantified and expressed as fold increase over that observed in normal controls via measurement of optical density using the Image lab 4 software (Bio-Rad).

For Western blot, the homogenate was subjected to SDS-PAGE and blotted using a polyvinylidene difluoride membrane, and then incubated with the primary antibody against nitrotyrosin (NT) (ab110282; Abcam) ${ }^{(40)}$. The enhancedchemiluminescence system was used to detect the signals.

The concentration of renal MDA was determined using a commercial kit according to the manufacturer's protocol (A003-1; Njjcbio). The activity of superoxide dismutase (SOD) (A001-1; Njjcbio) was measured as described by Gao et $a l{ }^{(28)}$.

\section{Statistical analysis}

All data are presented as means with their standard errors. The Shapiro-Wilk comparisons normality test was used to assess the distribution of all variables. Comparisons for normally distributed data between two groups were conducted using two-tailed $t$ test, and one- way ANOVA followed by Tukey's test for multiple comparisons. Mann-Whitney and Kruskal-Wallis tests were used for non-parametric analysis when data were non-normally distributed. $P<0.05$ was considered statistically significant. All analyses were carried out using SPSS 18.0 (SPSS Inc.). Graphs were generated using GraphPad Prism software version 5.0 (GraphPad Software, Inc.).

Calculation of sample size was performed by using the 'resource equation' method, as described by Charan \& Kantharia $^{(41)}$.

\section{Results}

KKAy mice were treated with NPD, LPD or LPD + KA from 12 to 24 weeks of age. Wild-type C57BL/6 J mice treated with NPD from 12 to 24 weeks of age served as the control group.

\section{Low-protein diet supplemented with ketoacids reduced albuminuria in diabetic mice.}

Fig. 1(a) shows that the ratio of 24-h urine albumin: urine creatinine in normal protein diet (NPD)-treated KKAy mice was significantly higher than that in control mice from 12 to 24 weeks of age. Treatment with LPD significantly reduced albuminuria in KKAy mice starting from 20 to 24 weeks of age; LPD +KA further reduced albuminuria at 20 and 24 weeks as compared with that observed with LPD treatment alone (Fig. 1 (a)). At 24 weeks, LPD + KA treatment reduced the ratio of 24 -h urine albumin:creatinine by $71 \%$ as compared with that observed with NPD treatment $(P=0 \cdot 00002)$.

KKAy mice had significantly lower level of serum albumin compared with control mice from 12 to 24 weeks of age (Fig. 1(b)). LPD significantly increased serum albumin levels in KKAy mice from 20 to 24 weeks of age, as compared with that with NPD treatment (Fig. 1(b)). LPD + KA treatment further increased serum albumin levels in KKAy mice at 20 and 24 weeks of age (Fig. 1(b)). At 24 weeks of age, the LPD + KA treatment elevated the serum albumin level by $39 \%$ as compared with that observed with NPD treatment (Fig. 1(b), $P=0.003$ ). No significant difference was observed between the four groups with respect to changes in serum creatinine level from 12 to 24 weeks of age (Fig. 1(c)).

\section{Low-protein diet supplemented with ketoacids prevented glomerular damage in diabetic mice.}

PAS staining showed that the glomerular mesangial matrix was accumulated in KKAy mice at 24 weeks of age compared with control mice (Fig. 2(a)). The relative mesangial area was significantly reduced by $36 \%$ by LPD treatment as compared with that observed in NPD-treated KKAy mice (Fig. 2(b), $P=0.02$ ). $\mathrm{LPD}+\mathrm{KA}$ treatment reduced the relative mesangial area by $58 \%$ as compared with that observed after NPD treatment (Fig. 2(b), $P=0.02$ ).

The thickness of GBM and podocyte foot process was assessed by electron microscopy. The thickness of GBM was 

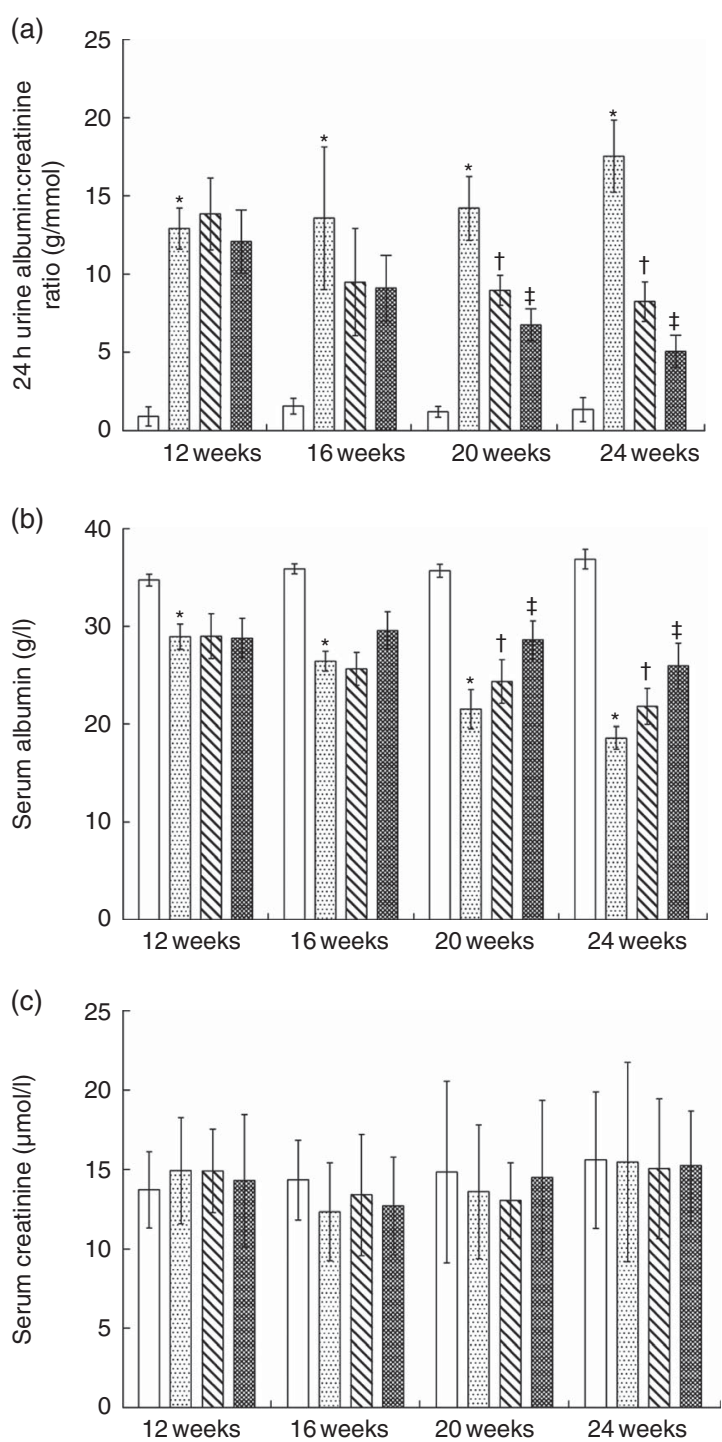

Fig. 1. Biochemical parameters of urine and serum in the experimental groups. $\square$, Control; $\square$, normal protein diet (NPD); $\$$, low-protein diets (LPD); $\otimes$, LPD supplemented with ketoacids. ${ }^{*} P<0.05 \mathrm{v}$. control; $\dagger P<0.05 \mathrm{v}$. NPD; $\ddagger P<0.05$ v. LPD.

increased by 2.5 -fold and podocyte foot process effacement was observed in KKAy mice at 24 weeks of age compared with control mice (Fig. 2(c) and (d)). The LPD treatment decreased glomerular basement thickness and improved the severity of the podocyte foot process effacement in KKAy mice; these beneficial effects were more profound in the LPD + KA group (Fig 2(c) and (d)). LPD + KA treatment reduced the thickness of GBM by $49 \%$ as compared with that achieved with NPD treatment $(P=0.03)$.

\section{Low-protein diet supplemented with ketoacids did not change} kidney weight and blood glucose levels in diabetic mice

The total body weight of NPD-treated KKAy mice was significantly greater than that of control mice from 12 to 24 weeks; LPD or LPD + KA treatment reduced the body weight of KKAy mice from 16 to 24 weeks of age (Fig. 3(a)). The two (a)

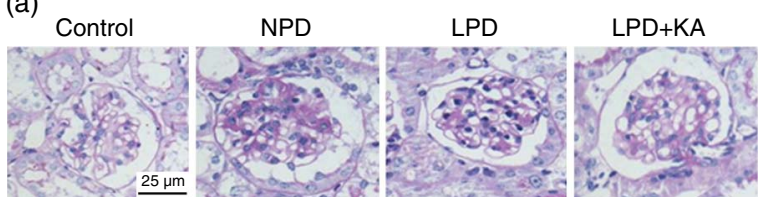

(b)

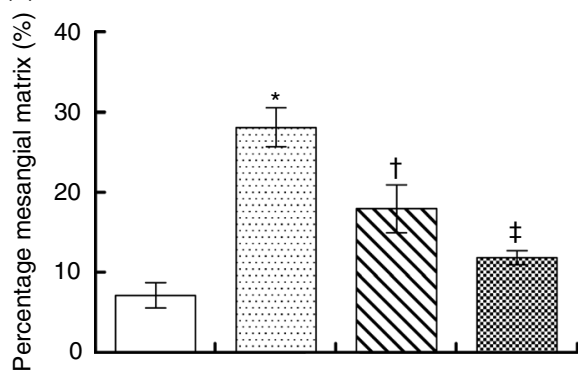

(c)

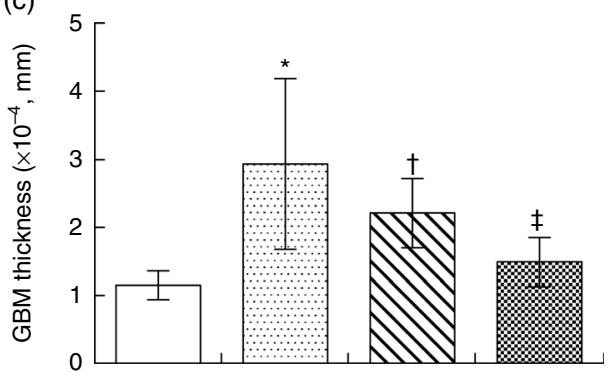

(d)

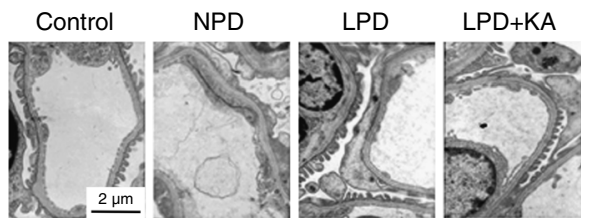

Fig. 2. Renal structural changes in KKAy diabetic mice after nutritional

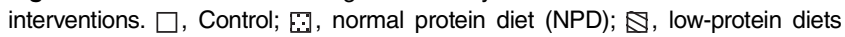
(LPD); 图, LPD supplemented with ketoacids (LPD +KA); GBM, glomerular basement membrane. * $P<0.05$ v. control; $† P<0.05$ v. NPD; $\ddagger P<0.05$ v. LPD.

kidney weight:total body weight (2KW:TBW) ratio was increased in the NPD-treated KKAy mice at 24 weeks of age compared with control mice; treatment with LPD or LPD + KA had no effect on the 2KW:TBW ratio (Fig. 3(b)).

Fasting blood glucose levels were measured throughout the treatment in all groups. Fasting blood glucose levels of KKAy mice were higher than those of control mice throughout the duration of the experiments; treatment with LPD or LPD + KA showed no effect on fasting blood glucose levels (Fig. 3 (c)).

\section{Low-protein diet supplemented with ketoacids ameliorated oxidative stress in diabetic mice}

To evaluate oxidative stress in kidneys of rats with diabetes, the concentration of MDA and the activity of SOD were measured at 24 weeks. The levels of renal MDA in the NPD-treated KKAy mice were higher than those in the control mice. Treatment with LPD and LPD + KA significantly reduced the levels of renal MDA (by 21 and $41 \%$, respectively) as compared with that observed 

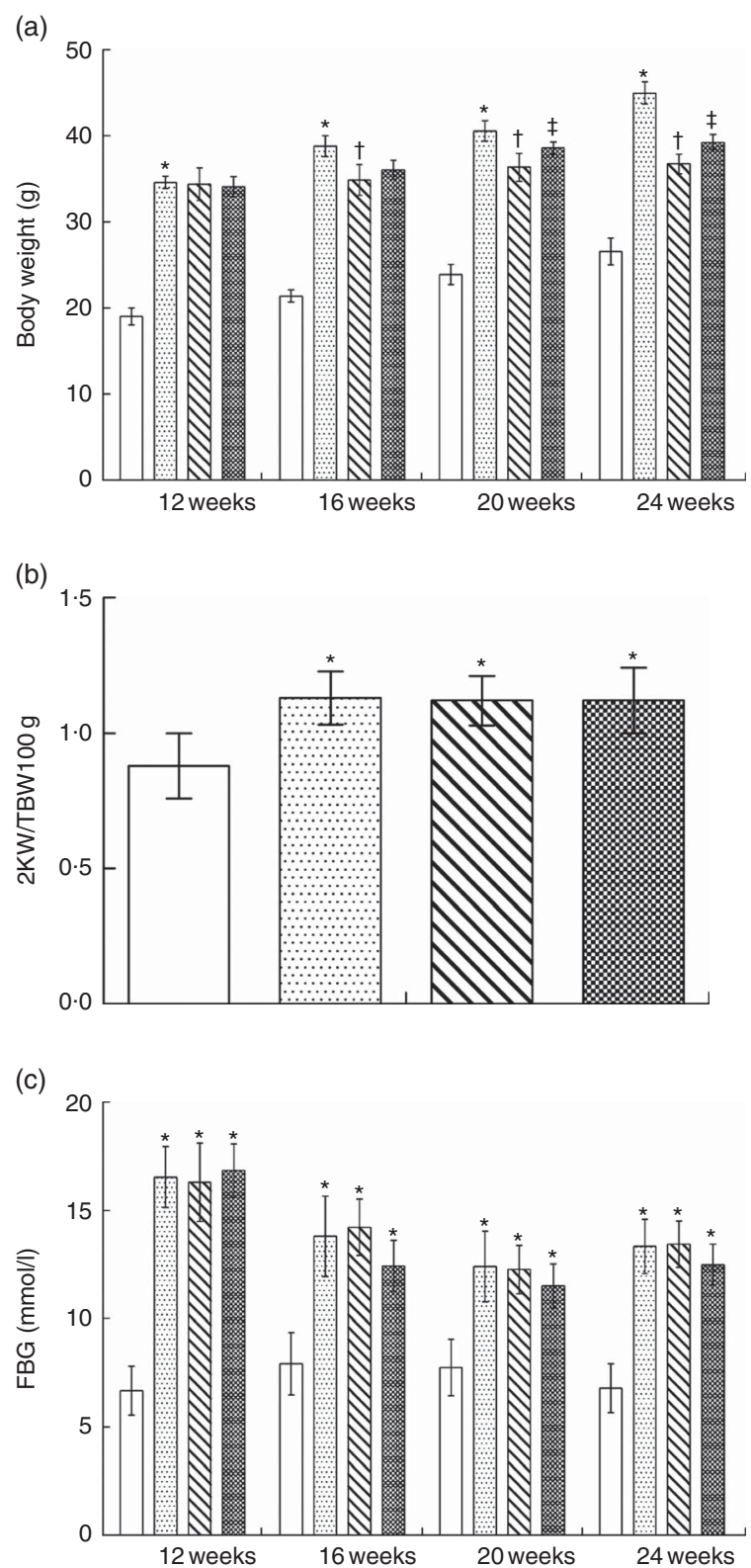

Fig. 3. Kidney weight, body weight and blood glucose levels in KKAy diabetic mice after nutritional interventions. $\square$, Control; $\because$, normal protein diet (NPD); $\$$, low-protein diets (LPD); $\otimes$, LPD supplemented with ketoacids; 2KW:TBW, two kidney weight:total body weight; FBG, fasting blood glucose. ${ }^{*} P<0.05 \mathrm{v}$. control; $\uparrow P<0.05$ v. NPD; $\ddagger P<0.05$ v. LPD.

after NPD treatment (Fig 4(a), $P=0 \cdot 01$ ). The activity of renal SOD in KKAy mice was lower than that in control mice (Fig. 4(b)). Interestingly, LPD treatment showed no effect on renal SOD activity (Fig. 4(b)). However, treatment with LPD + KA significantly increased renal SOD activity in KKAy mice (Fig. 4(b)).

The oxidative stress was further evaluated by measuring the production of NT in the kidneys. Western blot analysis showed that the expression of renal NT in the NPD-treated KKAy mice was higher than that in the control mice. Treatment with LPD significantly reduced the renal NT expression, which was further reduced by treatment with LPD + KA treatment
(Fig. 4(c)). Furthermore, results of oxyblot analysis revealed a 10 -fold increase in carbonyl formation in kidneys of KKAy mice as compared with that in control mice, which suggests increased oxidative stress of proteins in KKAy mice (Fig. 4(d)). LPD treatment showed no effect on carbonyl formation; however, LPD + KA treatment significantly reduced carbonyl formation (by $60 \%$ ) as compared with that observed with NPD treatment (Fig. 4(d), $P=0 \cdot 002$ ).

\section{Discussion}

KA have been prescribed alongside LPD to patients with $\mathrm{CKD}^{(42)}$. Previous studies have shown that LPD + KA has more pronounced beneficial effects than those of LPD alone with respect to impeding the progression of CKD and in delaying the need to initiate kidney replacement therapy ${ }^{(43)}$. Results of a meta-analysis suggest that protein diet restriction slows chronic renal disease progression in non-diabetic and type 1 diabetic patients, but not in type 2 diabetic patients ${ }^{(9)}$. Whether LPD + KA has beneficial effects in type $2 \mathrm{DN}$, especially in the early stage of DN, is not clear. In the current study, we focused on the effect of LPD + KA treatment in the early stages of DN, when the disease is still reversible. We showed that LPD retarded disease progression in an early type $2 \mathrm{DN}$ mouse model; the beneficial effects of LPD were further enhanced by supplementation of KA. We also found that treatment with LPD + KA attenuated the degree of renal oxidative stress in KKAy mice.

Abnormal intra-glomerular haemodynamics contributes to the progression of DN. Protein overload is one of the several molecular mechanisms that are believed to underlie abnormal intra-glomerular haemodynamics in $\mathrm{DN}^{(6)}$. The renoprotective effects of LPD have been demonstrated in animal models of $\mathrm{DN}^{(7,14)}$; further, positive results with use of LPD have been reported from several clinical trials on patients with $\mathrm{DN}^{(44,45)}$. However, the results from human studies have not been consistent in different experimental settings ${ }^{(6,9,46)}$. Protein overload activates the RAS, and LPD + KA has been shown to inhibit the intrarenal $\mathrm{RAS}^{(47)}$. Giordano et $a l^{(48)}$ found that a moderateprotein diet restriction $(0.7 \mathrm{~g} / \mathrm{kg}$ per $\mathrm{d}, 6 \mathrm{~d} /$ week $)$ was successful in the management of DN in elderly individuals with T2DM. In our study, we demonstrated the renoprotective effects of LPD in T2DM as shown by reduced albuminuria and ameliorated glomerular damage.

However, the risk of malnutrition is a key concern with the use of LPD in patients with $\mathrm{CKD}^{(10)}$; this is a particularly valid concern in patients with diabetes, in whom insulin deficiency can accelerate protein degradation ${ }^{(6)}$. LPD + KA has been shown to protect against malnutrition; for example, LPD + KA prevented muscle loss in $5 / 6$ nephrectomised rats ${ }^{(49)}$. A study by Huang et al. ${ }^{(13)}$ also supports the protective effect of $\mathrm{LPD}+\mathrm{KA}$ against muscle loss in rats with DN. Compared with NPD, LPD was shown to decrease nitrogenous waste products $^{(50)}$ in the short term. However, long-term treatment with LPD was shown to enhance protein catabolism, which may lead to malnutrition; this is the most common complication of LPD treatment ${ }^{(10)}$. KA have excess $\mathrm{N}$ residues that can be used for production of $\mathrm{EAA}^{(51)}$. Treatment with $\mathrm{LPD}+\mathrm{KA}$ helps 
(a)

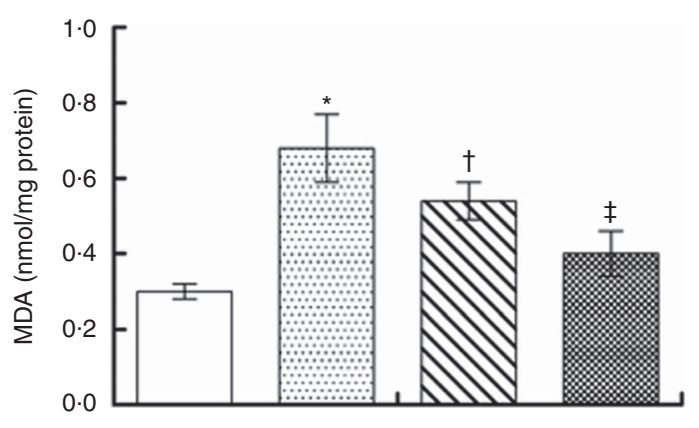

(c)
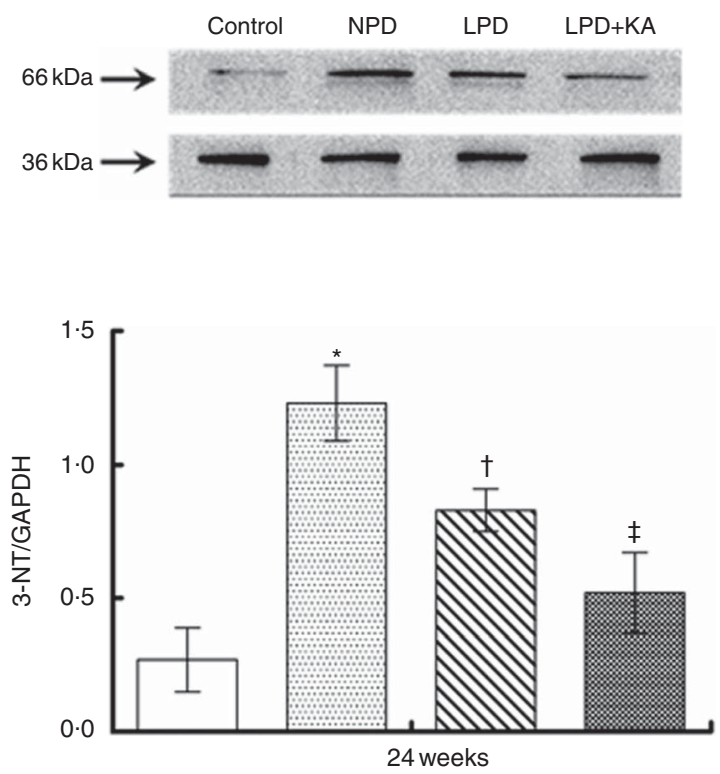

(b)

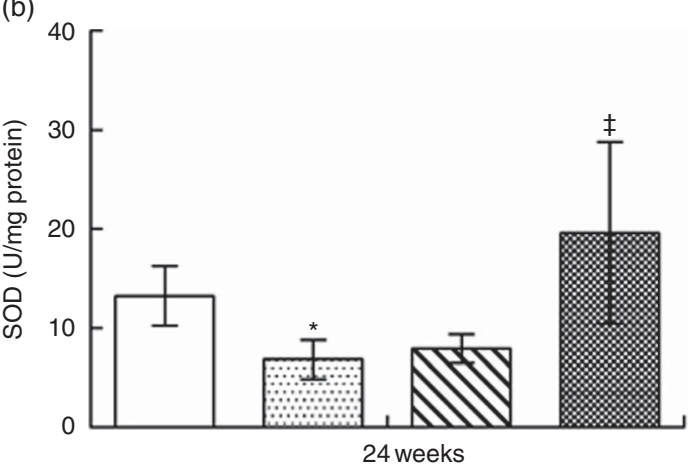

(d)
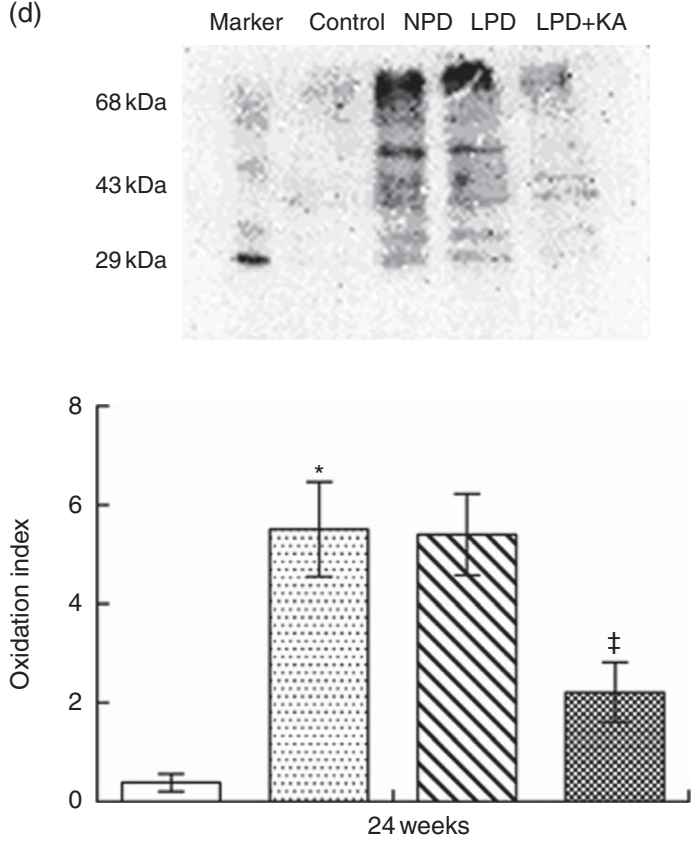

Fig. 4. Amelioration of oxidative stress in KKAy diabetic mice by low-protein diet (LPD) and ketoacids (KA). $\square$, Control; $\square$, normal protein diet (NPD); $\$$, LPD; $⿴$, LPD supplemented with KA (LPD + KA); MDA, malondialdehyde; SOD, superoxide dismutase; NT, nitrotyrosin; GAPDH, glyceraldehyde-3-phosphate dehydrogenase. ${ }^{*} P<0.05$ v. control; † $P<0.05$ v. NPD; $¥ P<0.05$ v. LPD.

maintain neutral $\mathrm{N}$ balance by reducing protein catabolism and oxidation of amino acids ${ }^{(28)}$. Thus, we postulated that LPD + KA improves nutritional status in a mouse model of early type 2 DN, over and above that achieved with LPD treatment alone. In the current study, we found that the serum albumin levels were decreased in diabetic mice and were remarkably recovered by LPD + KA treatment, but only slightly recovered by LPD treatment. These findings suggest that supplementation of KA improved the nutritional status of diabetic mice. In addition, we found that supplementation of KA conferred an additional benefit in $\mathrm{DN}$ as shown by further reduced albuminuria and improved glomerular structure after LPD treatment.

We explored the renal protective mechanism of LPD + KA in a mouse model of early type $2 \mathrm{DN}$. In DN, there is an imbalance in the oxidant and antioxidant system, which leads to increased production of $\operatorname{ROS}^{(1,18,52)}$. Oxidation of important macromolecules including proteins, lipids, carbohydrates and DNA can be used as markers of oxidative stress ${ }^{(19,22)}$. Peuchant et $a l .{ }^{(53)}$ found that very LPD + KA in chronic renal failure had an antioxidant effect. Indeed, a mild anti-oxidative effect of LPD was also observed in our study. KA have been shown to function as effective antioxidants and protect rat spermatozoa against exposure to $\mathrm{H}_{2} \mathrm{O}_{2}^{(54)}$. In our previous study, supplementation of KA displayed renal protection against oxidative stress in 5/6 nephroctomised rat kidneys ${ }^{(28)}$. We therefore hypothesised that KA confer renal benefits through inhibiting oxidative stress in DN. This hypothesis was confirmed by our findings; LPD + KA treatment decreased production of renal MDA, reduced the expression of 3-NT and downregulated protein carbonylation, alongside up-regulation of renal SOD activity in diabetic mice. These findings were either not observed or were observed to a lesser degree in diabetic mice treated with LPD alone.

The concentration of fasting blood glucose was assessed during the study, and we found that neither LPD nor LPD + KA treatment reduced the elevated concentration of blood glucose in diabetic mice, which suggests that renoprotective effect of LPD or LPD + KA treatment was independent of hyperglycaemia control. 
KA compound powder was used as a supplement in our study and in several other animal experiments ${ }^{(47,49)}$. However, the specific components of KA compound power, which are responsible for the renoprotective effect, are not known. KA supplements normally contain substantial amounts of 4-methyl-2-oxovaleric acid, the KA analogue of leucine (ketoleucine), which may suppress protein degradation ${ }^{(31,55)}$. KA supplements may also promote net protein anabolism and suppress urea formation, although the underlying mechanisms are not well characterised ${ }^{(55)}$.

There are several limitations in our study. First, only four biomarkers for oxidative stress were measured in our study. More assays should be performed to fully characterise the antioxidant effect of LPD + KA in follow-up experiments. Second, the average daily consumption of feed for each mouse was not calculated, although the three kinds of diet used in this study contain the same number of energy content. Third, in the present study, we had only ten animals per group, which is a relatively small size. However, the number is large enough to ensure adequate statistical power by using the 'resource equation' method ${ }^{(41)}$, which is a crude method based on law of diminishing return. Although the method cannot be considered as robust as power analysis method, it is easy. Importantly, we first calculated the sample size with the software of NCSS-PASS 11.0 based on the thickness of GBM in this study. When sample size is nine, the power is 0.9283 and the effect size is $0.7012(\alpha=0.05, \beta=0 \cdot 0717)$. We next calculated the sample size with the software of NCSS-PASS 11.0 again based on the result of urine protein, which was performed previously by Zhang et $a l^{(47)}$. According to this calculation, the statistic power is 0.92817 and the effect size is $0.701(\alpha=0.05, \beta=0.07183)$ when the sample size is nine. Thus, we believe that the same sample size ( $n$ 10) used in our experiment is large enough for statistical analysis.

Protein-restricted diets plus KA is considered as a valid therapeutic approach for patients with $\mathrm{CKD}^{(42)}$. Our study showed that the renoprotective effect of LPD $+\mathrm{KA}$ in the early stage of type $2 \mathrm{DN}$ is mediated by inhibition of oxidative stress.

\section{Acknowledgements}

This work was supported by National Natural Science Foundation of China (81700579, 81670612) to C. M., the Three-year Project of Action for Shanghai Public Health System (GWIV-18) to C. M. and National Key Research and Development Program of China (2016YFC0901502) to C. M.

C. M. conceived and coordinated the study. D. L. and M. W. wrote the paper. D. L., L. L., S. M., B. Y. and L. F. designed, performed and analysed the experiments shown in Fig. 1-3. D. L. and X. G. designed, performed and analysed the experiments shown in Fig. 4. All authors reviewed the results and approved the final version of the manuscript.

None of the authors has any conflicts of interest to declare.

\section{References}

1. Miranda-Diaz AG, Pazarin-Villasenor L, Yanowsky-Escatell FG, et al. (2016) Oxidative stress in diabetic nephropathy with early chronic kidney disease. J Diabetes Res 2016, 7047238.
2. Willingham F (2012) The dietary management of patients with diabetes and renal disease: challenges and practicalities. J Ren Care 38, Suppl. 1, 40-51.

3. Chan GC \& Tang SC (2015) Diabetic nephropathy: landmark clinical trials and tribulations. Nephrol Dial Transplant 31, 359-368.

4. Gu J, Yang M, Qi N, et al. (2016) Olmesartan prevents microalbuminuria in $\mathrm{db} / \mathrm{db}$ diabetic mice through inhibition of angiotensin II/p38/SIRT1-induced podocyte apoptosis. Kidney Blood Press Res 41, 848-864.

5. Brenner BM MT \& Hostetter TH (1982) Dietary protein intake and the progressive nature of kidney disease: the role of hemodynamically mediated glomerular injury in the pathogenesis of progressive glomerular sclerosis in aging, renal ablation, and intrinsic renal disease. $N$ Engl J Med 307, 652-659.

6. Otoda T, Kanasaki K \& Koya D (2014) Low-protein diet for diabetic nephropathy. Curr Diab Rep 14, 523.

7. Ran J, Ma J, Liu Y, et al. (2014) Low protein diet inhibits uric acid synthesis and attenuates renal damage in streptozotocininduced diabetic rats. J Diabetes Res 2014, 287536.

8. Piccoli GB, Vigotti FN, Leone F, et al. (2015) Low-protein diets in CKD: how can we achieve them? A narrative, pragmatic review. Clin Kidney J 8, 61-70.

9. Rughooputh MS, Zeng R \& Yao Y (2015) Protein diet restriction slows chronic kidney disease progression in non-diabetic and in type 1 diabetic patients, but not in type 2 diabetic patients: a meta-analysis of randomized controlled trials using glomerular filtration rate as a surrogate. PLOS ONE 10, $\mathrm{e} 0145505$.

10. Noce A, Vidiri MF, Marrone G, et al. (2016) Is low-protein diet a possible risk factor of malnutrition in chronic kidney disease patients? Cell Death Discov 2, 16026.

11. Shah BV \& Patel ZM (2016) Role of low protein diet in management of different stages of chronic kidney disease practical aspects. BMC Nephrol 17, 156.

12. Kalantar-Zadeh K, Cano NJ, Budde K, et al. (2011) Diets and enteral supplements for improving outcomes in chronic kidney disease. Nat Rev Nephrol 7, 369-384.

13. Huang J, Wang J, Gu L, et al. (2013) Effect of a low-protein diet supplemented with ketoacids on skeletal muscle atrophy and autophagy in rats with type 2 diabetic nephropathy. PLOS ONE 8, e81464.

14. Yang X, Yang M, Cheng M, et al. (2015) Effects of low-protein diets supplemented with ketoacid on expression of TGF-beta and its receptors in diabetic rats. Biomed Res Int 2015 , 873519.

15. Mac-Moune Lai F, Szeto CC, Choi PC, et al. (2004) Isolate diffuse thickening of glomerular capillary basement membrane: a renal lesion in prediabetes? Mod Pathol 17, 1506-1512.

16. Molitch ME, DeFronzo RA, Franz MJ, et al. (2004) Nephropathy in diabetes. Diabetes Care 27, S79-S83.

17. Forbes JM, Coughlan MT \& Cooper ME (2008) Oxidative stress as a major culprit in kidney disease in diabetes. Diabetes $\mathbf{5 7}$, $1446-1454$

18. Asmat U, Abad K \& Ismail K (2016) Diabetes mellitus and oxidative stress - a concise review. Saudi Pharm J 24, $547-553$

19. Kumawat M, Sharma TK, Singh I, et al. (2013) Antioxidant enzymes and lipid peroxidation in type 2 diabetes mellitus patients with and without nephropathy. N Am J Med Sci 5 , 213-219.

20. Fatani SH, Babakr AT, NourEldin EM, et al. (2016) Lipid peroxidation is associated with poor control of type-2 diabetes mellitus. Diabetes Metab Syndr 10, S64-S67. 
21. Zheng H, Wu J, Jin Z, et al. (2016) Protein modifications as manifestations of hyperglycemic glucotoxicity in diabetes and its complications. Biochem Insights 9, 1-9.

22. Elmarakby AA \& Sullivan JC (2012) Relationship between oxidative stress and inflammatory cytokines in diabetic nephropathy. Cardiovasc Ther 30, 49-59.

23. Domingueti CP, Dusse LM, Carvalho M, et al. (2016) Diabetes mellitus: the linkage between oxidative stress, inflammation, hypercoagulability and vascular complications. $J$ Diabetes Complications 30, 738-745.

24. Zhang MZ, Wang X, Yang H, et al. (2017) Lysophosphatidic acid receptor antagonism protects against diabetic nephropathy in a type 2 diabetic model. J Am Soc Nephrol 37, ASN2017010101

25. Yang S, Zhao L, Han Y, et al. (2017) Probucol ameliorates renal injury in diabetic nephropathy by inhibiting the expression of the redox enzyme p66Shc. Redox Biol 13, 482-497.

26. Wan J, Hou X, Zhou Z, et al. (2017) WT1 ameliorates podocyte injury via repression of EZH2/beta-catenin pathway in diabetic nephropathy. Free Radic Biol Med 108 280-299.

27. Gao X, Huang L, Grosjean F, et al. (2011) Low-protein diet supplemented with ketoacids reduces the severity of renal disease in 5/6 nephrectomized rats: a role for KLF15. Kidney Int 79, 987-996.

28. Gao X, Wu J, Dong Z, et al. (2010) A low-protein diet supplemented with ketoacids plays a more protective role against oxidative stress of rat kidney tissue with 5/6 nephrectomy than a low-protein diet alone. Br J Nutr 103, 608-616.

29. Soler MJ, Riera M \& Batlle D (2012) New experimental models of diabetic nephropathy in mice models of type 2 diabetes: efforts to replicate human nephropathy. Exp Diabetes Res 2012, 616313.

30. Reeves PG (1997) Components of the AIN-93 diets as improvements in the AIN-76A Diet. J Nutr 127, 5 Suppl., 838S-841S

31. Shah AP, Kalantar-Zadeh K \& Kopple JD (2015) Is there a role for ketoacid supplements in the management of CKD? Am J Kidney Dis 65, 659-673.

32. Wolley MJ, Wu A, Xu S, et al. (2017) In primary aldosteronism, mineralocorticoids influence exosomal sodium-chloride cotransporter abundance. J Am Soc Nephrol 28, 56-63.

33. Gai Z, Gui T, Hiller C, et al. (2016) Farnesoid X receptor protects against kidney injury in uninephrectomized obese mice. J Biol Chem 291, 2397-2411.

34. Ishikawa Y, Ito T, Tanimoto M, et al. (2012) Podocyte loss and albuminuria of KK-Ay mouse: a spontaneous animal model for human type 2 diabetic nephropathy. J Diabetes Mellitus $\mathbf{2}$, 346-352.

35. Ito T, Tanimoto $\mathrm{M}$, Yamada $\mathrm{K}$, et al. (2006) Glomerular changes in the KK-Ay/Ta mouse: a possible model for human type 2 diabetic nephropathy. Nephrology 11, 29-35.

36. Pei Z, Okura T, Nagao T, et al. (2016) Osteopontin deficiency reduces kidney damage from hypercholesterolemia in apolipoprotein E-deficient mice. Sci Rep 6, 28882.

37. Wang Y, Shi LL, Wang LY, et al. (2015) Protective effects of MDG-1, a polysaccharide from Opbiopogon japonicus on diabetic nephropathy in diabetic KKAy Mice. Int J Mol Sci 16, 22473-22484

38. Ernst $O$ \& Zor $T$ (2010) Linearization of the Bradford protein assay. J Vis Exp 38, e1918-e1918.
39. Lee YJ, Kwon SB, Kim CH, et al. (2015) Oxidative damage and nuclear factor erythroid 2-related factor 2 protein expression in normal skin and keloid tissue. Ann Dermatol 27, 507-516.

40. Shu L, Vivekanandan-Giri A, Pennathur S, et al. (2014) Establishing 3-nitrotyrosine as a biomarker for the vasculopathy of Fabry disease. Kidney Int 86, 58-66.

41. Charan J \& Kantharia ND (2013) How to calculate sample size in animal studies? J Pharmacol Pharmacother 4, 303-306.

42. Aparicio M, Bellizzi V, Chauveau P, et al. (2012) Proteinrestricted diets plus keto/amino acids - a valid therapeutic approach for chronic kidney disease patients. J Ren Nutr $\mathbf{2 2}$, S1-S21.

43. Garneata L \& Mircescu G (2013) Effect of low-protein diet supplemented with keto acids on progression of chronic kidney disease. J Ren Nutr 23, 210-213

44. Nezu U, Kamiyama H, Kondo Y, et al. (2013) Effect of low-protein diet on kidney function in diabetic nephropathy: meta-analysis of randomised controlled trials. BMJ Open 3, e002934.

45. Koya D, Haneda M, Inomata S, et al. (2009) Long-term effect of modification of dietary protein intake on the progression of diabetic nephropathy: a randomised controlled trial. Diabetologia 52, 2037-2045.

46. Kiuchi A, Ohashi Y, Tai R, et al. (2016) Association between low dietary protein intake and geriatric nutrition risk index in patients with chronic kidney disease: a retrospective singlecenter cohort study. Nutrients 8, 662-674.

47. Zhang JY, Yin Y, Ni L, et al. (2016) Low-protein diet supplemented with ketoacids ameliorates proteinuria in $3 / 4$ nephrectomised rats by directly inhibiting the intrarenal reninangiotensin system. Br J Nutr 116, 1491-1501.

48. Giordano M, Ciarambino T, Castellino P, et al. (2014) Longterm effects of moderate protein diet on renal function and low-grade inflammation in older adults with type 2 diabetes and chronic kidney disease. Nutrition 30, 1045-1049.

49. Wang DT, Lu L, Shi Y, et al. (2014) Supplementation of ketoacids contributes to the up-regulation of the Wnt7a/Akt/ p70S6K pathway and the down-regulation of apoptotic and ubiquitin-proteasome systems in the muscle of $5 / 6$ nephrectomised rats. Br J Nutr 111, 1536-1548.

50. Michael T, Pedrini ASL, Joseph Lau, Chalmers TC \& Wang PH (1996) The effect of dietary protein restriction on the progression of diabetic and nondiabetic renal diseases: a meta-analysis. Ann Intern Med 124, 627-632.

51. Adeva MM, Calvino J, Souto G, et al. (2012) Insulin resistance and the metabolism of branched-chain amino acids in humans. Amino Acids 43, 171-181.

52. Newsholme P, Cruzat VF, Keane KN, et al. (2016) Molecular mechanisms of ROS production and oxidative stress in diabetes. Biochem J 473, 4527-4550.

53. Peuchant E, Delmas-Beauvieux MC, Dubourg L, et al. (1997) Antioxidant effects of a supplemented very low protein diet in chronic renal failure. Free Radic Biol Med 22, 313-320.

54. Li SF, Liu HX, Zhang YB, et al. (2010) The protective effects of alpha-ketoacids against oxidative stress on rat spermatozoa in vitro. Asian J Androl 12, 247-256.

55. Meisinger E \& Strauch M (1985) The influence of two different essential amino acid keto analogue preparations on the clinical status of patients with chronic renal failure. Z Ernahrungswiss 24, 96-104. 